\title{
Alternating Copolymerization Realized with Alternating Transformation of Anion Migrated Ring-Opening Polymerization and Anionic Polymerization
}

\section{Mechanisms}

Hongyuan Bai, Li Han, Chao Li, Songbo Zhang, Xuefei Wang, Yu Yin, Xiaolu Zhang, Hongwei Ma*

Department of Polymer Science and Engineering, School of Chemical Engineering, Dalian University of Technology, Dalian 116024, China

*E-mail: mahw@dlut.edu.cn

Table of the Content

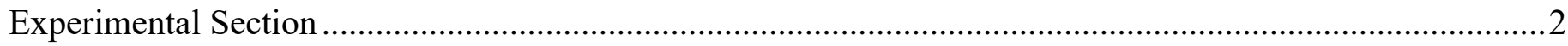

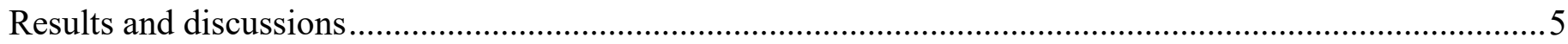

The results of elementary reaction in the copolymerization of DPE derivatives and CPVB ........................6

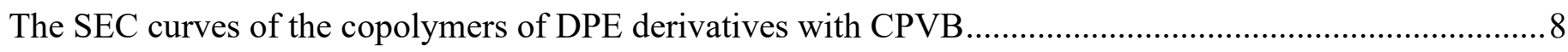

The MALDI-TOF-MS spectra of the copolymers of DPE derivatives with CPVB ....................................9

${ }^{13} \mathrm{C}$ NMR and DEP $135^{\circ}{ }^{13} \mathrm{C}$ NMR spectra of the copolymer of DPE with CPVB (Run 1) ......................... 10

${ }^{1} \mathrm{H}$ NMR spectra of the deprotected polymer for Runs 3-4 and Runs 6-7 ............................................. 14

The calculation equation of monomer units for binary copolymerization of DPE-R and CPVB................. 14

The calculation equation of monomer units for terpolymerization of DPE and DPE-R with CPVB.............15

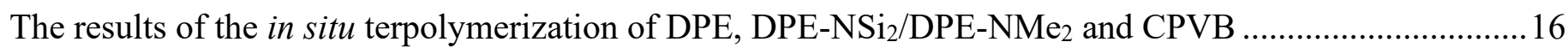

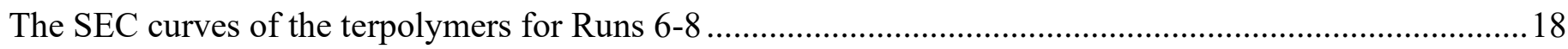

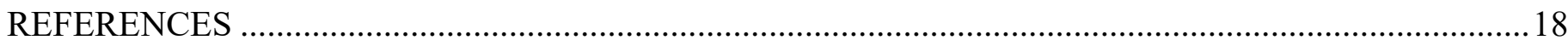




\section{Experimental Section}

\section{Materials}

Cyclopropyl phenyl ketone (TCI, 98\%), 1,1-Diphenyl-ethylene (Aldrich, 97\%), 4-aminobenzophenone (Energy Chemical, 98\%), 4-(Dimethylamino)benzophenone (Energy Chemical, 97\%), chlorotrimethylsilane (Energy Chemical, 98.0\%), benzene (Sinopharm, 99\%), tetrahydrofuran (THF) (Sinopharm, 99\%), tert-BuOK (Energy Chemical, 98\%), methyltriphenylphosphonium bromide (Energy Chemical, 98\%), tetrabutylammonium fluoride (Energy Chemical, 98\%), n-butyllithium (n-BuLi, J\&K Chemical, $1.6 \mathrm{M}$ solution in hexanes) and sec-butyllithium (sec-BuLi, J\&K Chemical, 1.3 M solution in hexanes) were used as purchased for purification as received unless otherwise stated.

The purification process for tetrahydrofuran (THF) and benzene were carried out under high vacuum conditions, as in the procedures detailed in our previous report. ${ }^{1}$ The purchased high concentration sec-BuLi was first diluted with benzene in vacuum glove box, then the diluted sec-BuLi (1.0 mL) was added into 10.0 $\mathrm{ml}$ deionized water containing phenolphthalein, titrate with $0.02633 \mathrm{M}$ dilute hydrochloric acid solution, repeat three times. According to $\mathrm{C}_{\mathrm{HCl}} \mathrm{V}_{\mathrm{HCl}}=\mathrm{C}_{s e c-\mathrm{BuLi}} \mathrm{V}_{\text {sec-BuLi}}$, the initiator concentration of each titration can be calculated, the average of three groups of initiator concentration is the accurate concentration and the concentrations of sec-BuLi as $0.2525 \mathrm{M}$ in benzene were determined. Similarly, the concentrations of secBuLi as $0.298 \mathrm{M}$ in $\mathrm{C}_{6} \mathrm{D}_{6}$ were determined with the above method.

\section{Instrumentation}

${ }^{1} \mathrm{H}$ nuclear magnetic resonance (NMR, $\left.5 \mathrm{wt} \%, \mathrm{CDCl}_{3}\right)$ spectra were recorded on a Bruker Avancell 400 MHz NMR spectrometer with $\left(\mathrm{CH}_{3}\right)_{4} \mathrm{Si}$ (tetramethylsilane, TMS) as the internal standard. Size exclusion chromatography (SEC) was performed on a Waters HPLC component system (2414 refractive index detector) at a flow rate of $1.0 \mathrm{~mL} \mathrm{~min}{ }^{-1}$ in THF at $30{ }^{\circ} \mathrm{C}$ after calibration using polystyrene standards. MALDI-TOFMS analysis was performed on a Waters MALDI micro MX mass spectrometer (Waters, Milford, CT, USA) with 2-[(2E)-3-(4-tertbutylphenyl)-2-methyprop-2-enylidene] malonitrile (DCTB) and silver trifluoroacetate as dopants. Gas chromatography/triple quadrupole mass spectrometry (EI source, American Agilent Corporation, 7000B), differential scanning calorimetry (DSC, TA, Q20). Sample preparation details were mentioned in our previous report. ${ }^{1}$

\section{Synthesis of CPVB, DPE-NSi 2 and DPE-NMe 2 .}

The synthetic process of CPVB, DPE-NSi 2 and DPE-NMe 2 has been detail described in our previous report. ${ }^{2-}$ 


\section{Elementary reaction of DPE/DPE-NSi $2 /$ DPE-NMe ${ }_{2}$ with CPVB}

All the polymerization processes were performed in a glovebox.

The elementary reaction of DPE/DPE-NSi $/ 2$ DPE-NMe 2 with CPVB are the same, thus the elementary reaction of DPE and CPVB was taken as an example. Due to the self-growth propagation rate of DPE and CPVB is equal to zero at room temperature, thus only the cross-propagation reaction of DPE/CPVB and CPVB-Li/DPELi should be carried out. DPE $(0.02 \mathrm{~g}, 0.111 \mathrm{mmol})$ in $1 \mathrm{~mL}$ of $\mathrm{C}_{6} \mathrm{D}_{6}$ was initiated by adding $372.6 \mu \mathrm{L}$ of sec$\operatorname{BuLi}(0.298 \mathrm{M}, 0.111 \mathrm{mmol})$ at the ordinary temperature for an hour and the solution was in wine red. Then, CPVB (0.016 g, $0.111 \mathrm{mmol})$ was injected into the mixture at the ordinary temperature and the solution was immediately transferred to a sealed NMR tube, and the whole process was monitored by in situ ${ }^{1} \mathrm{H}$ NMR spectroscopy at the ordinary temperature, and the NMR spectra were collected every other minute. Similarly, CPVB (0.016 g, $0.111 \mathrm{mmol})$ in $1 \mathrm{~mL}$ of $\mathrm{C}_{6} \mathrm{D}_{6}$ was initiated by adding $372.6 \mu \mathrm{L}$ of sec-BuLi $(0.298 \mathrm{M}, 0.111$ $\mathrm{mmol}$ ) at the ordinary temperature for a day (in order to ensure that all CPVB monomer is converted into active species $)$ and the solution was in light yellow. Then, DPE $(0.02 \mathrm{~g}, 0.111 \mathrm{mmol})$ was injected into the mixture at the ordinary temperature and the solution was immediately transferred to a sealed NMR tube, and the whole process was monitored by in situ ${ }^{1} \mathrm{H}$ NMR spectroscopy at the ordinary temperature, and the NMR spectra were collected every other minute.

${ }^{1} \mathrm{H}$ NMR peaks of the adducts:

Elementary reaction of CPVB-Li with DPE for Figure S1: 7.55-6.92 (Aromatic), 6.10-5.74 (-C=CH- AMRO of CPVB), 5.42-5.30 (-C= $\mathrm{CH}_{2}$ - for DPE).

Elementary reaction of DPE-Li with CPVB for Figure S1: 7.68-6.62 (Aromatic), 6.80-6.60 (-C=CH- AMRO of CPVB), 5.37-4.90 (-C= $\mathrm{CH}_{2}$ - for $\left.\mathrm{CPVB}\right)$.

Elementary reaction of CPVB-Li with DPE-NSi 2 for Figure S1: 7.60-6.24 (Aromatic), 5.87-5.60 (-C=CHAMRO of CPVB), 5.37-5.16 (-C=CH2- for DPE-NSi 2 ).

Elementary reaction of DPE-NSi 2 -Li with CPVB for Figure S1: 7.42-6.14 (Aromatic), 5.22-5.15 (-C=CHAMRO of CPVB), 5.10-4.64 (-C= $\mathrm{CH}_{2}$ - for $\left.\mathrm{CPVB}\right)$.

Elementary reaction of CPVB-Li with DPE-NMe 2 for Figure S1: 7.71-6.46 (Aromatic), 6.00-5.75 (-C=CHAMRO of CPVB), 5.55-5.28 (-C=CH- for DPE-NMe 2$)$.

Elementary reaction of DPE-NMe 2 -Li with CPVB for Figure S1: 7.80-6.00 (Aromatic), 5.40-5.28 (-C=CHAMRO of CPVB), 5.48-5.82 (-C= $\mathrm{CH}_{2}$ - for $\left.\mathrm{CPVB}\right)$.

The peaks of the first monitored ${ }^{1} \mathrm{H}$ NMR spectrum was also detailed attributed to the corresponding structure 
of the adducts in Figure S1.

\section{Binary copolymerization of DPE/DPE-NSi 2 /DPE-NMe 2 with CPVB}

All the polymerization processes were performed in a glovebox.

The binary copolymerization of DPE/DPE-NSi $2 / \mathrm{DPE}^{-\mathrm{NMe}_{2}}$ with CPVB are the same, thus the copolymerization of DPE and CPVB was taken as an example. DPE (0.125 g, $0.695 \mathrm{mmol}$ for Run 1) in $3 \mathrm{~mL}$ of benzene was initiated by adding $91.6 \mu \mathrm{L}$ of sec-BuLi $(0.2525 \mathrm{M}, 0.023 \mathrm{mmol})$ at the ordinary temperature for half hour and the solution was in wine red. Then, CPVB $(0.1 \mathrm{~g}, 0.695 \mathrm{mmol})$ was injected into the mixture. After 5 days, the reaction was quenched by adding isopropanol $(0.5 \mathrm{~mL})$ and the products were precipitated with excess methanol and dried to a constant weight in a vacuum oven. All the obtained products were white powder.

\section{Terpolymerization of DPE and /DPE-NSi 2 /DPE-NMe 2 with CPVB}

All the polymerization processes were performed in a glovebox.

One-step process. The terpolymerization of DPE and DPE-NSi $2 / \mathrm{DPE}-\mathrm{NMe}_{2}$ with CPVB are the same, thus the terpolymerization of DPE and DPE-NSi 2 with CPVB was taken as an example (Run S1). DPE (0.0625 g, $0.347 \mathrm{mmol})$ in $1.7 \mathrm{~mL}$ of $\mathrm{C}_{6} \mathrm{D}_{6}$ was initiated by adding $116.45 \mu \mathrm{L}$ of sec-BuLi $(0.298 \mathrm{M}, 0.0347 \mathrm{mmol})$ at room temperature for half hour and the solution was in wine red. Then, CPVB $(0.1 \mathrm{~g}, 0.695 \mathrm{mmol})$ and DPE$\mathrm{NSi}_{2}(0.118 \mathrm{~g}, 0.347 \mathrm{mmol})$ were injected into the mixture at the ordinary temperature and the solution was immediately transferred to a sealed NMR tube, and the whole process was monitored by in situ ${ }^{1} \mathrm{H}$ NMR spectroscopy at the ordinary temperature, and the NMR spectra were collected every other minute. After the reaction was nearly achieved, the reaction was quenched by adding isopropanol $(0.5 \mathrm{~mL})$ and isolating the filtrate. The obtained product was white powder.

Multi-step process. DPE $(0.183 \mathrm{~g}, 1.02 \mathrm{mmol})$ in $9 \mathrm{~mL}$ of benzene was initiated by adding $126.31 \mu \mathrm{L}$ of sec$\operatorname{BuLi}(0.2525 \mathrm{M}, 0.0319 \mathrm{mmol})$ at the ordinary temperature for half hour and the solution was in wine red. Then, CPVB (0.293 g, $2.03 \mathrm{mmol})$ was injected into the mixture. After 5 days DPE-NSi 2 (0.345 g, $1.02 \mathrm{mmol})$ were added into the remaining solution. After 5 days, the reaction was quenched by adding isopropanol $(0.5$ $\mathrm{mL}$ ) and the products were precipitated with excess methanol and dried to a constant weight in a vacuum oven. The obtained polymer was white powder.

\section{Deprotection of the polymers containing DPE-NSi $i_{2}$ units}

The deprotection process is the same for the polymers containing DPE-NSi 2 units, thus the deprotection of copolymer of DPE-NSi 2 and CPVB was carried out as an example (Run 3). $0.05 \mathrm{~g}$ copolymer of DPE-NSi 2 
and CPVB and dry THF (10 mL) were added into $50 \mathrm{~mL}$ round bottom flask, then tetrabutylammonium fluoride $(0.054 \mathrm{~g}, 0.207 \mathrm{mmol})$ in $5 \mathrm{~mL}$ of THF was added into the round bottom flask and stirring for a day. Consequently, the products were precipitated with excess methanol and dried to a constant weight in a vacuum oven.

\section{Results and discussions}

Investigation of the microstructure of the copolymer of DPE derivatives with CPVB

Through analysis of the NMR $\left({ }^{1} \mathrm{H},{ }^{13} \mathrm{C}\right.$, HSQC and HMBE) spectra of the PCPVB in Figure S6, the peak of the double bond in PCPVB (=C*H-) was split to double peaks and the two peaks was correspond to two unsaturated tertiary carbon atoms in CPVB units (5.49 ppm correspond to $128.97 \mathrm{ppm} ; 5.27 \mathrm{ppm}$ correspond to $127.24 \mathrm{ppm}){ }^{2}$ Moreover, through analysis of the HMBC spectrum, the two split double bond peaks in ${ }^{1} \mathrm{H}$ NMR was long-range correlated to two $-\mathrm{CH}_{2}$ in ${ }^{13} \mathrm{C}$ NMR (5.27 ppm correspond to $39.2 \mathrm{ppm}$ and $5.49 \mathrm{ppm}$ correspond to $28.2 \mathrm{ppm}$, respectively.). Suzuki and coworkers had reported that the stereochemistry of the double bond in $\mathrm{P}(2-\mathrm{PB})$ can be distinguished by the chemical shifts of the $-\mathrm{CH}_{2}$ which was adjacent to double bonds (i.e., $E$-structure was in $36.8 \mathrm{ppm}$ and $Z$-structure was in $40.0 \mathrm{ppm}$ ). ${ }^{5}$ The structure of PCPVB was similar to $\mathrm{P}(2-\mathrm{PB})$, thus the $-\mathrm{CH}_{2}$ in $39.2 \mathrm{ppm}$ can be attributed to $Z$-structure and $-\mathrm{CH}_{2}$ in 28.2 ppm was attributed to $E$-structure. Therefore, the multiplicity of the double bond in PCPVB was caused by stereochemistry (E-structure was $92.6 \%$ and $Z$-structure was $7.4 \%$ which was calculated by the area of the unsaturated tertiary carbon atoms). As characterized by NMR $\left({ }^{1} \mathrm{H},{ }^{13} \mathrm{C}, \mathrm{HSQC}\right.$ and $\left.\mathrm{HMBC}\right)$ spectra of the copolymer of CPVB with DPE in Figure S5, the two peaks of the split double bond $\left(=\mathrm{C}^{*} \mathrm{H}-\right.$ in CPVB units) were also corresponding to different unsaturated tertiary carbon atoms and the chemical shift of the tertiary carbon atoms exhibited similar situations as the $=\mathrm{CH}$ - units in PCPVB ( $E$-structure: $4.76 \mathrm{ppm}$ correspond to $135.63 \mathrm{ppm}$; Z-structure: $5.11 \mathrm{ppm}$ correspond to $129.04 \mathrm{ppm})$. Thus, the multiplicity of the double bond in the copolymer of CPVB with DPE derivatives was also caused by stereochemistry, and the content of $E$ - or 
$Z$ - structure can also be calculated by the area of the unsaturated tertiary carbon atoms, respectively. Additionally, the calculation method of the microstructure of the CPVB unit in the copolymer of DPE$\mathrm{NSi}_{2} / \mathrm{DPE}-\mathrm{NMe}_{2}$ and CPVB was same as the copolymer of DPE and CPVB (see Figures S7-8). The detailed results about the microstructure content in the copolymer of DPE derivatives with CPVB were listed in Table 1.

\section{The results of elementary reaction in the copolymerization of DPE derivatives and CPVB}

Table S1. The kinetic constant results of the elementary reactions in the copolymerization of CPVB with DPE derivatives

\begin{tabular}{cccc}
\hline DPE-R & $\begin{array}{c}{[\text { CPVB]/[DPE-R }]} \\
\text { feed ratio }\end{array}$ & $\begin{array}{c}\text { Temp } \\
\left({ }^{\circ} \mathrm{C}\right)\end{array}$ & $\begin{array}{c}10^{-4} k_{\mathrm{CD}}{ }^{\mathrm{b})} \\
\left(\left(\mathrm{L} / \mathrm{mol}^{1 / 2} \mathrm{~min}^{-1}\right)\right.\end{array}$ \\
\hline DPE & $1 / 1$ & 20 & 20.7 \\
DPE-NSi $_{2}$ & $1 / 1$ & 20 & 2.06 \\
DPE-NMe $_{2}$ & $1 / 1$ & 20 & 2.89 \\
\hline
\end{tabular}

a) Experimental temperature. b) kinetic constant of the elementary reaction. 

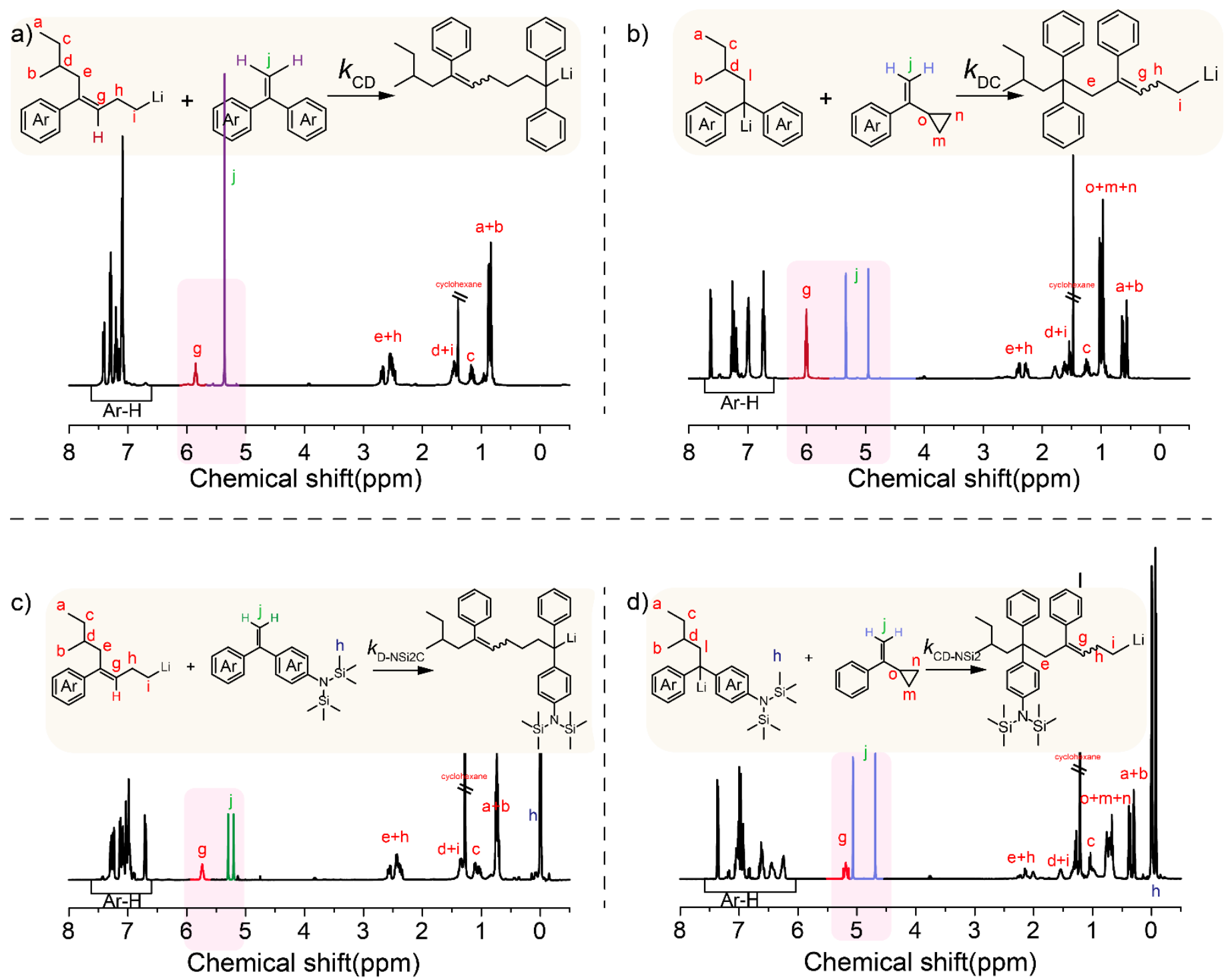

e)

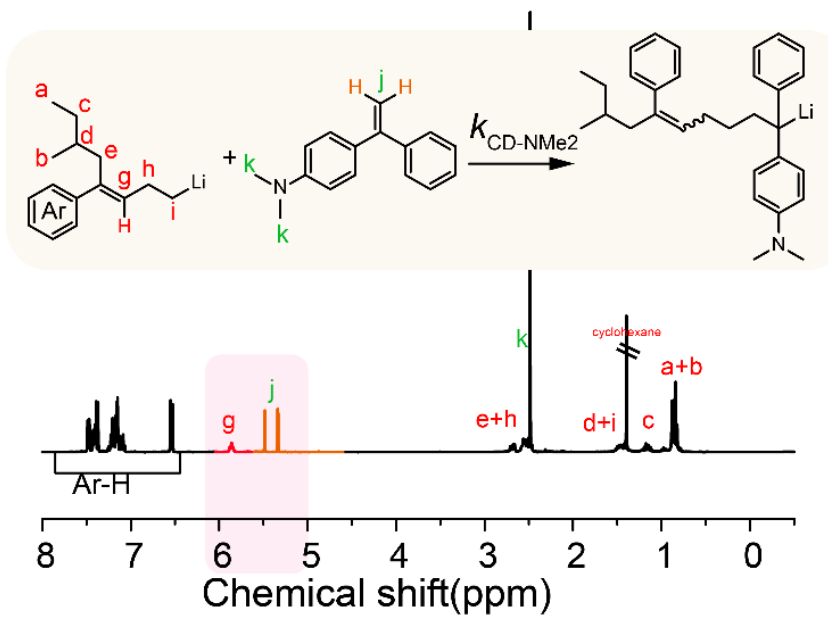

f)

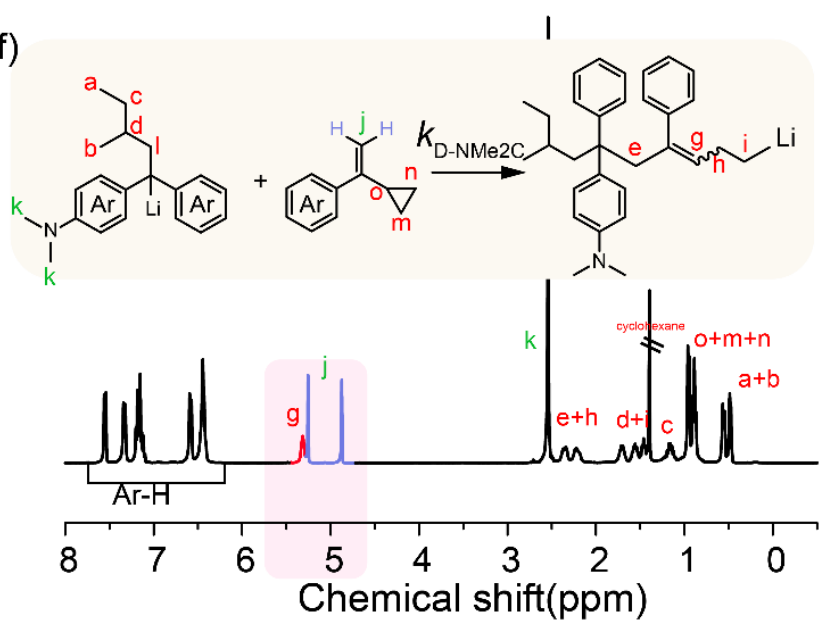

Figure S1. The first monitored in situ ${ }^{1} \mathrm{H}$ NMR spectra results of elementary reaction. a, c, e) for the first

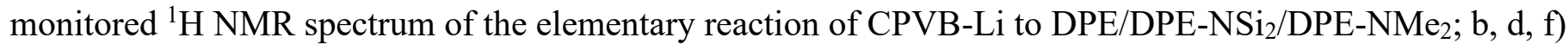
for the first monitored ${ }^{1} \mathrm{H}$ NMR spectrum of the elementary reaction of DPE-Li/DPE-NSi $2-\mathrm{Li} / \mathrm{DPE}-\mathrm{NMe}_{2}-\mathrm{Li}$ to CPVB. 
The NMR spectra in Figure S1 was the first monitored NMR spectrum for each elementary reaction. When the second reaction monomer (DPE/DPE-NSi $/$ DPE-NMe $/$ CPVB) was injected into the special initiator (CPVB-Li/DPE-Li/DPE-NSi 2 -Li/DPE-NMe $2-\mathrm{Li}$ ) in $\mathrm{C}_{6} \mathrm{D}_{6}$ in the elementary reaction, the solution of the reaction was immediately transferred to a sealed NMR tube and as soon as possible to monitor the process of the reaction. Owing to the low addition rate in the elementary reaction of CPVB-Li to DPE/DPE-NSi $/ 2$ DPE$\mathrm{NMe}_{2}$, thus the Figure S7 a, c, e can represent the early stage of the addition reaction. However, the higher addition rate in the elementary reaction of DPE-Li /DPE-NSi $2-\mathrm{Li} / \mathrm{DPE}-\mathrm{NMe}_{2}-\mathrm{Li}$ to CPVB resulting in a new double bond of CPVB unit was observed in the first monitored NMR spectrum (Figure S1 b, d, f), thus the first monitored NMR spectrum only detected middle or late stage of the reaction, which result in an incredible kinetic result (i.e., the $k_{\mathrm{DC}}$ ).

\section{The SEC curves of the copolymers of DPE derivatives with CPVB}

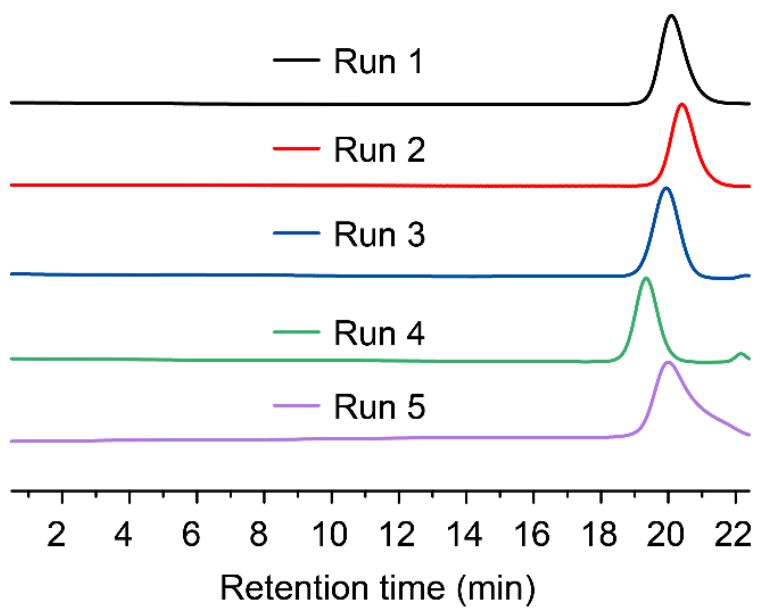

Figure S2. The SEC curves of the copolymers of DPE derivatives with CPVB (Runs 1-5). 
The MALDI-TOF-MS spectra of the copolymers of DPE derivatives with CPVB
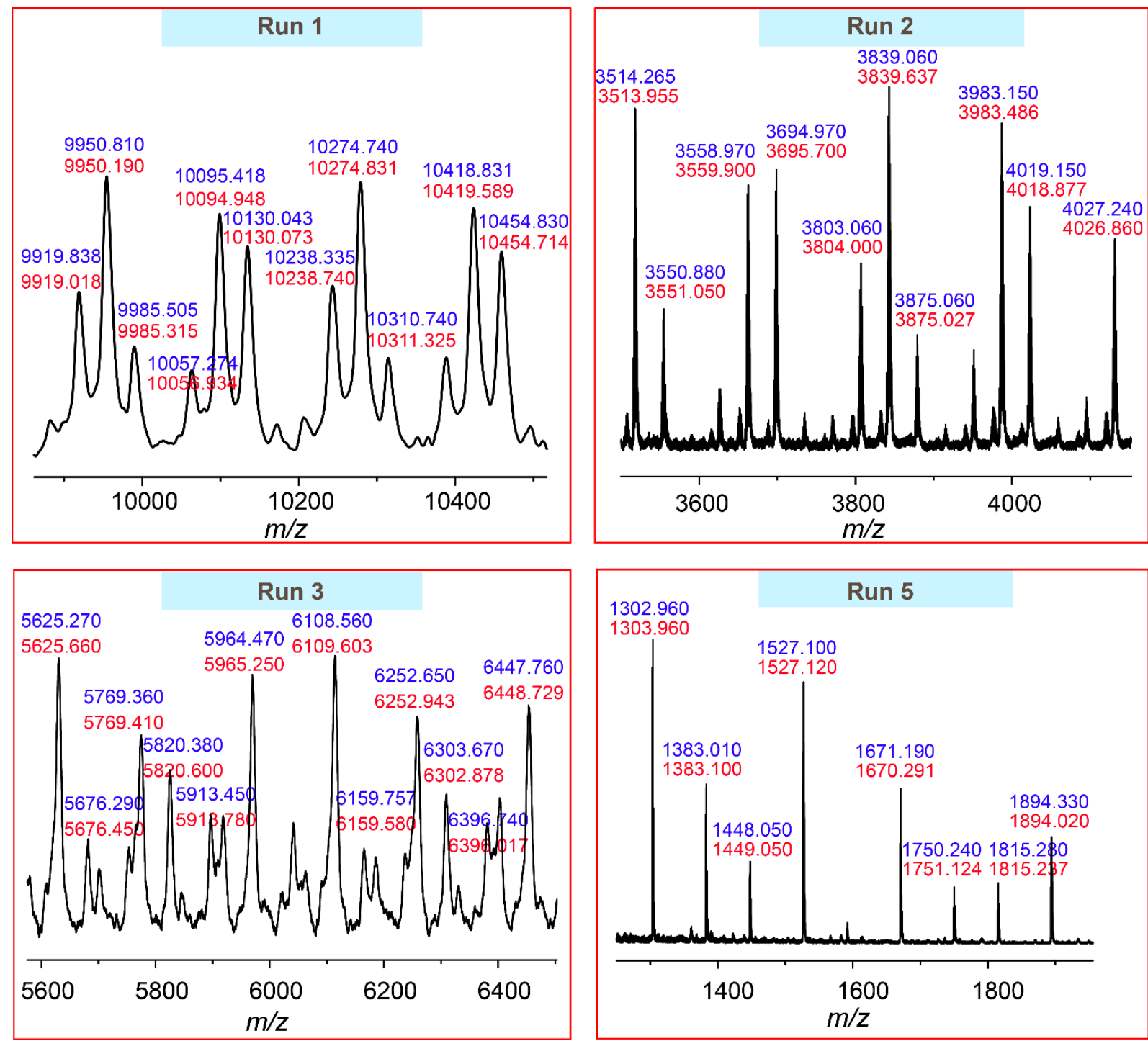

Figure S3. MALDI-TOF-MS spectra of the copolymers of DPE derivatives with CPVB (Runs 1,2 for the copolymer of DPE with CPVB. Runs 3 for the copolymer of DPE-NSi2 with CPVB. Runs 4 for the copolymer of DPE-NMe 2 with CPVB ). 


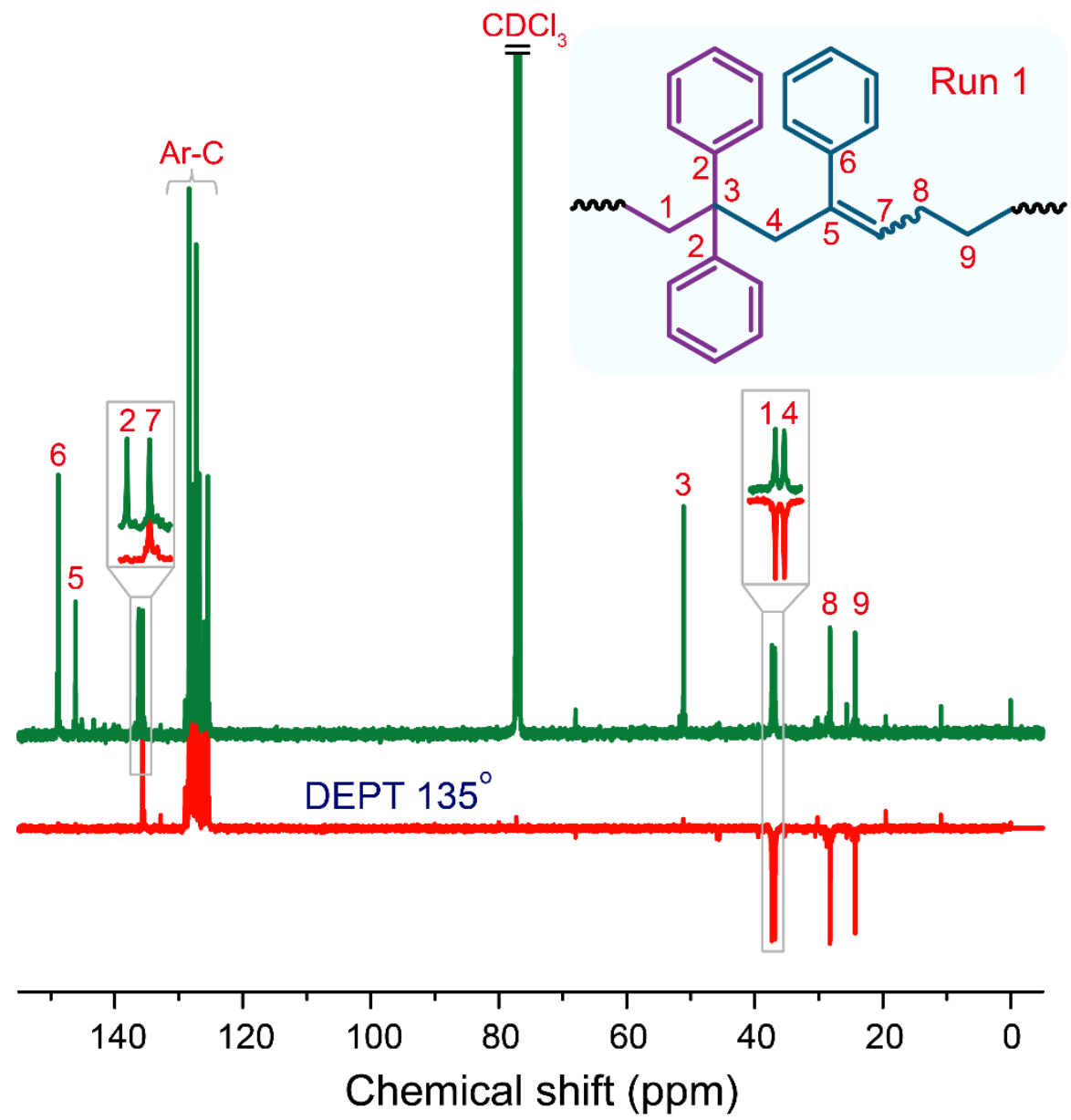

Figure S4. ${ }^{13} \mathrm{C}$ NMR and DEP $135^{\circ}{ }^{13} \mathrm{C}$ NMR spectra of the copolymer of DPE with CPVB (Run 1). 

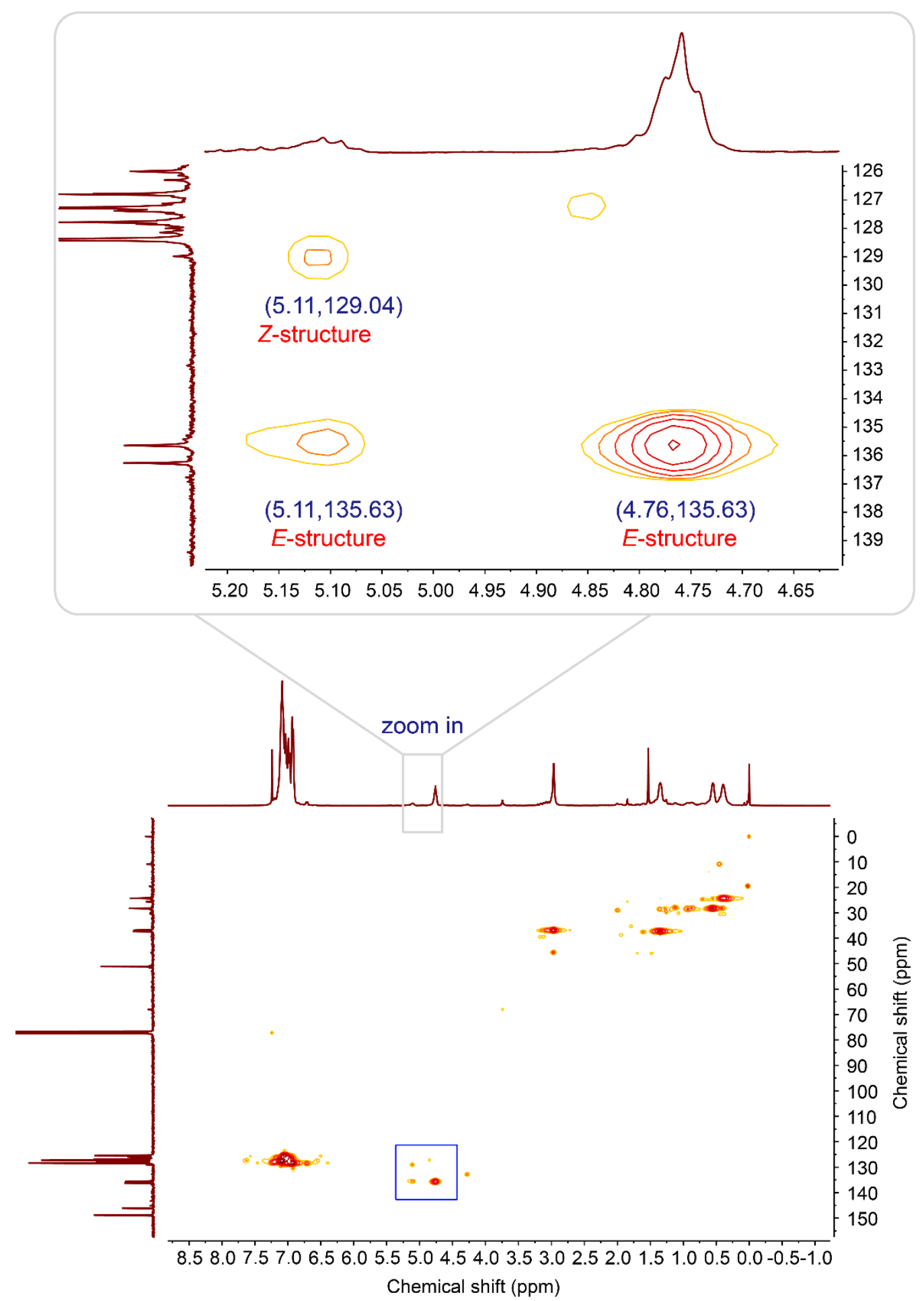

Figure S5. ${ }^{1} \mathrm{H}-{ }^{13} \mathrm{C}$ NMR and HSQC spectra results of the copolymer of DPE and CPVB. 


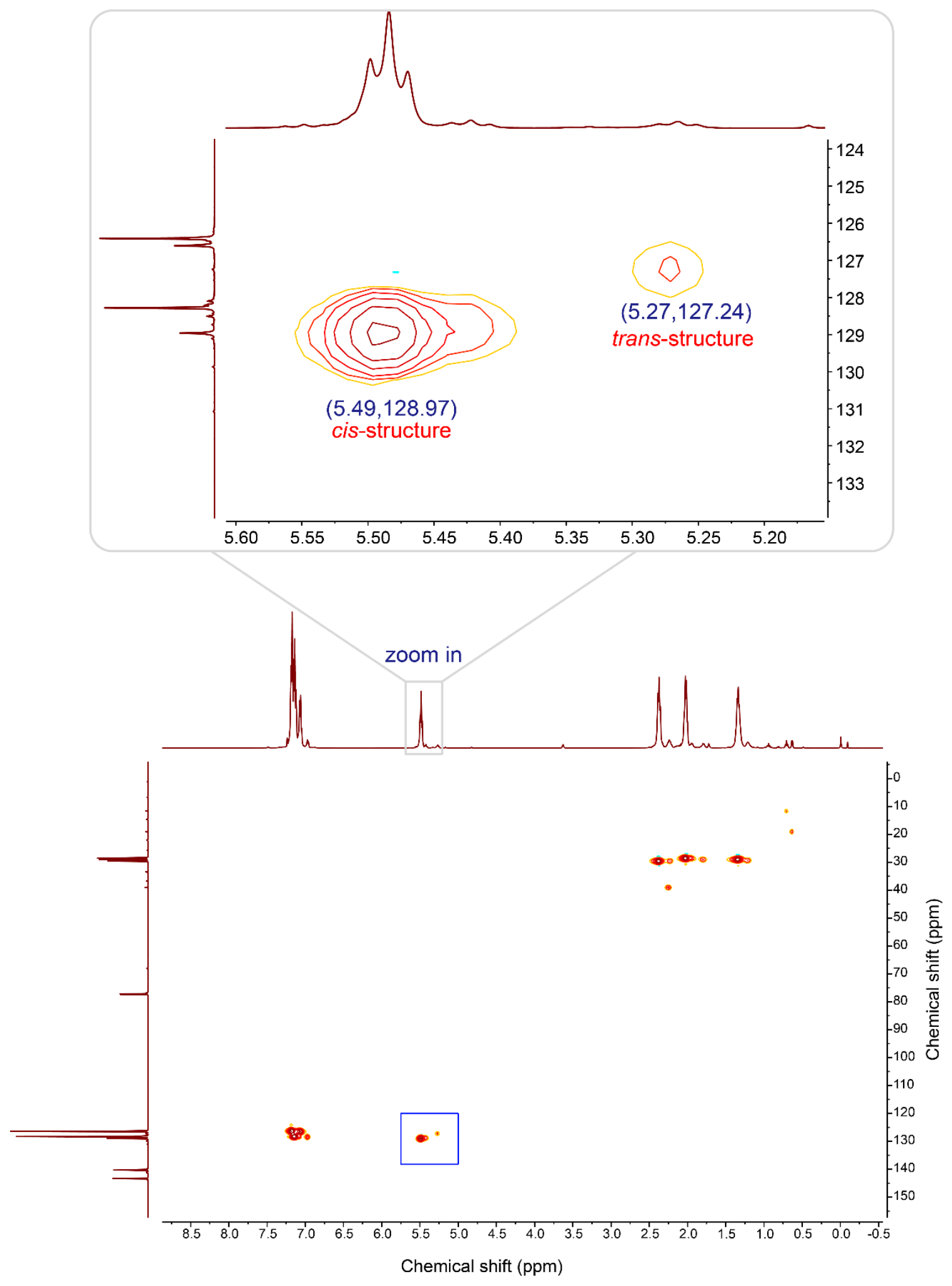

Figure S6. ${ }^{1} \mathrm{H}-{ }^{13} \mathrm{C}$ NMR and HSQC spectra results of the homopolymerization of CPVB at $60{ }^{\circ} \mathrm{C}^{2}$ (the polymer was obtained from ref. 2) 

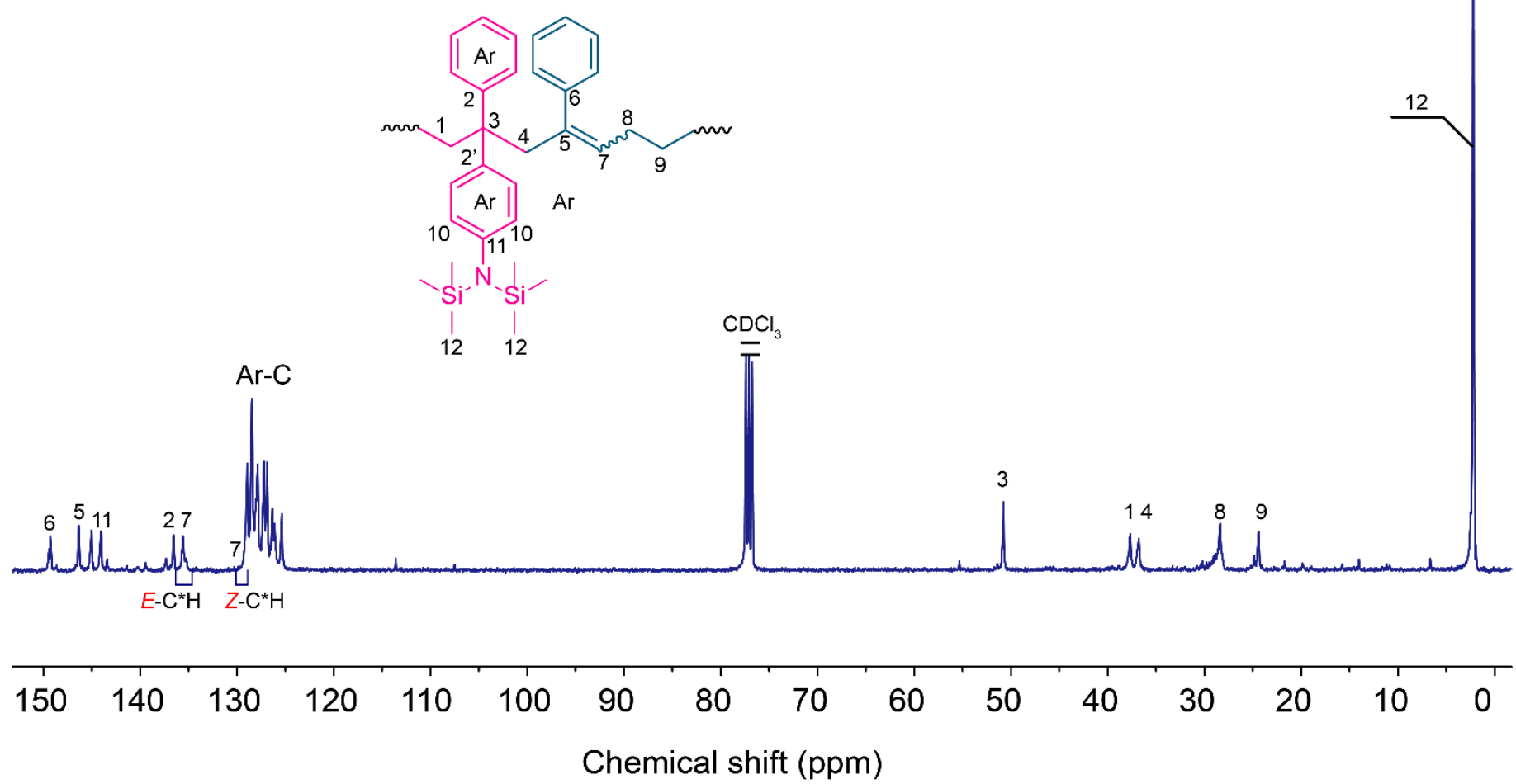

Figure S7. ${ }^{13} \mathrm{C}$ NMR spectrum of the copolymer of DPE-NSi $i_{2}$ with CPVB (Run 3).

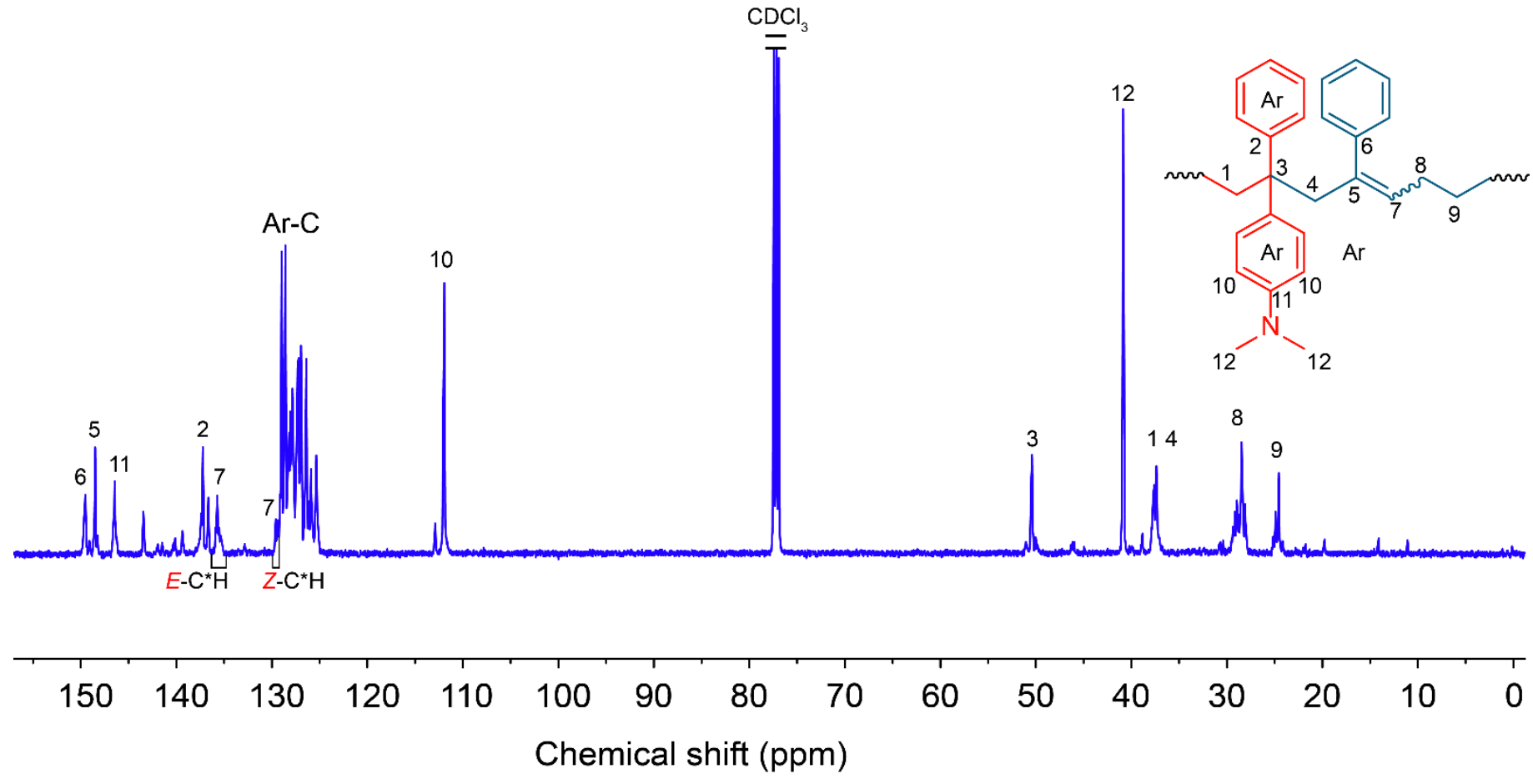

Figure S8. ${ }^{13} \mathrm{C}$ NMR spectrum of the copolymer of DPE-NMe 2 with CPVB (Run 5). 


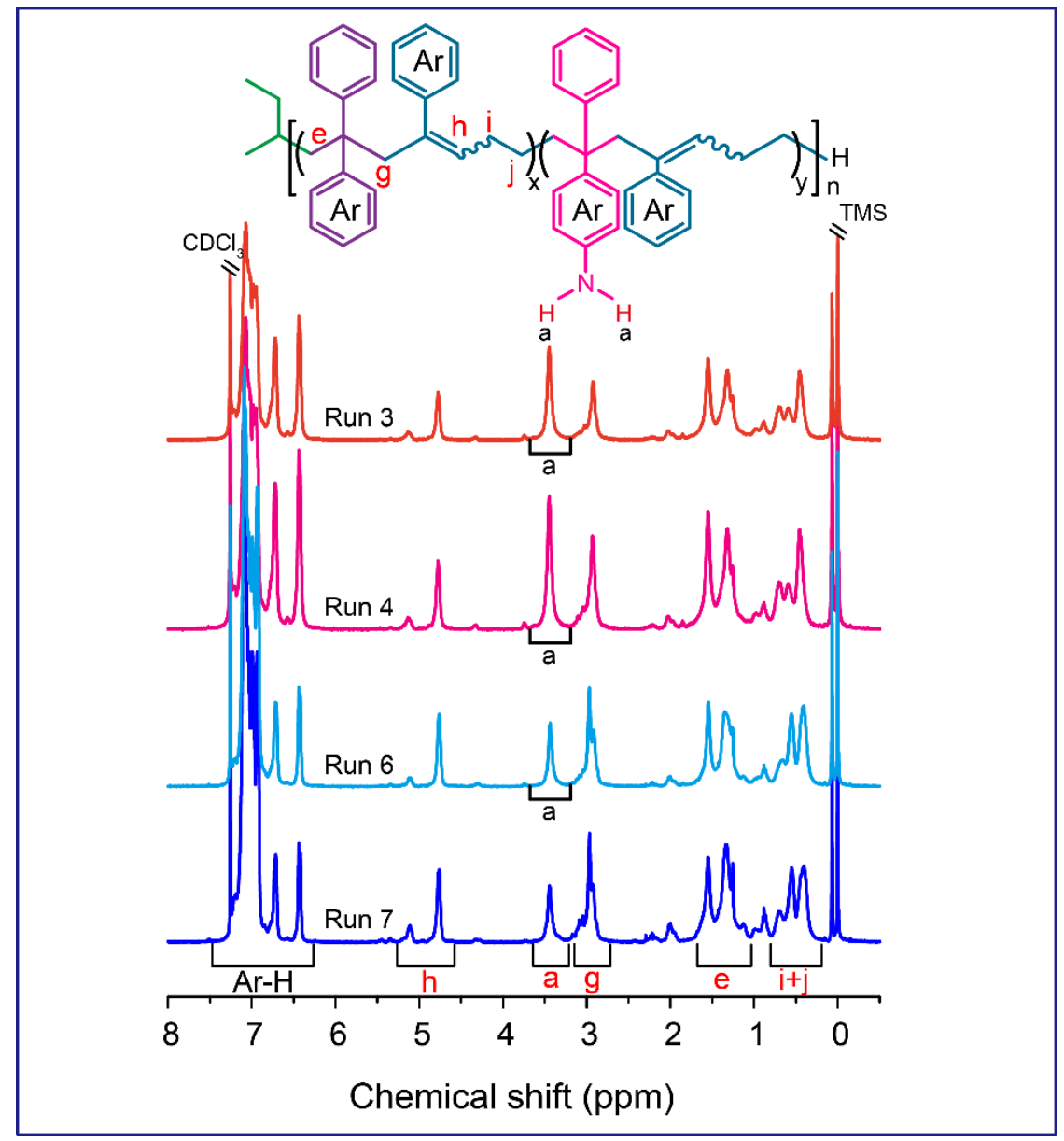

Figure S9. ${ }^{1} \mathrm{H}$ NMR spectra of the deprotected polymers for Runs 3, 4, 6, 7 .

The calculation equation of monomer units for binary copolymerization of DPE-R and CPVB

Note: Integral area of two $\mathrm{CH}_{3}$ in sec-butyl were defined as 6.0

$\mathrm{Nc}=($ Area $(\delta 5.3-4.6) \times 144.09) / 144.09$

Equation S1

$\mathrm{N}_{\mathrm{DPE}}=($ Area $(\delta 7.5-6.5)-$ Area $(\delta 7.26-7.24)-5 \times \mathrm{Nc}) / 10$

Equation S2

$\mathrm{N}_{\text {DPE-NMe2 }}=(\operatorname{Area}(\delta 7.5-6.5)-$ Area $(\delta 7.26-7.24)-5 \times \mathrm{Nc}) / 9$

Equation S3

$\mathrm{N}_{\text {DPE-NSi2 }}=($ Area $(\delta 3.8-3.2)) / 2$

Equation S4 
The calculation equation of monomer units for terpolymerization of DPE and DPE-R with CPVB

Note: Integral area of two $\mathrm{CH}_{3}$ in sec-butyl were defined as 6.0

$\mathrm{Nc}=($ Area $(\delta 5.3-4.6) \times 144.09) / 144.09 \quad$ Equation S5

$\mathrm{N}_{\text {DPE-NSi2 }}=($ Area $(83.8-3.2)) / 2 \quad$ Equation S6

$\mathrm{N}_{\text {DPE-NMe2 }}=($ Area $(\delta 2.95-2.66) / 6 \quad$ Equation S7

$\mathrm{N}_{\mathrm{DPE}}=\left(\right.$ Area $(87.5-6.5)$-Area $(\delta 7.26-7.24)-5 \times \mathrm{Nc}-9 \times \mathrm{N}_{\text {DPE-NMe2 }}$ or $\left.\mathrm{N}_{\text {DPE-NSi2 }}\right) / 10 \quad$ Equation $\mathrm{S} 8$ 
The results of the in situ terpolymerization of DPE, DPE-NSi $2 / \mathrm{DPE}-\mathrm{NMe}_{2}$ and CPVB

Table S2. The results of the in situ terpolymerization of DPE, DPE-NSi $2 / \mathrm{DPE}-\mathrm{NMe}_{2}$ and CPVB

\begin{tabular}{|c|c|c|c|c|c|c|c|c|}
\hline Run & DPE-R 1 & DPE-R 2 & $\begin{array}{c}{\left[\mathrm{D}_{1}\right] /[\mathrm{CPVB}] /\left[\mathrm{D}_{2}\right]} \\
\text { feed ratio }\end{array}$ & $\begin{array}{c}10^{-4} k_{\mathrm{app}, \mathrm{CPVB}}^{\mathrm{b})} \\
\left(\mathrm{min}^{-1}\right)\end{array}$ & $\begin{array}{c}10^{-4} k_{\mathrm{app}, \mathrm{D} 1}^{\mathrm{b})} \\
\left(\mathrm{min}^{-1}\right)\end{array}$ & $\begin{array}{c}10^{-4} k_{\mathrm{app}, \mathrm{D} 2}^{\mathrm{b})} \\
\left(\mathrm{min}^{-1}\right)\end{array}$ & $\begin{array}{c}\left.M \mathrm{n}^{\mathrm{c}}\right) \\
\left(\mathrm{g} \mathrm{mol}^{-1}\right)\end{array}$ & $\bigoplus^{\mathrm{c})}$ \\
\hline S1 & DPE & DPE-NSi2 & $0.5 / 1 / 0.5$ & 2.20 & 2.66 & 1.54 & 6100 & 1.16 \\
\hline S2 & DPE & DPE-NMe2 & $0.5 / 1 / 0.5$ & 3.84 & 7.23 & 1.78 & 5500 & 1.22 \\
\hline
\end{tabular}

a) Experimental temperature. b) The apparent kinetic constants. c) $M_{\mathrm{n}}$ and $\oslash$ values of the copolymers were determined using SEC with PS as a standard.

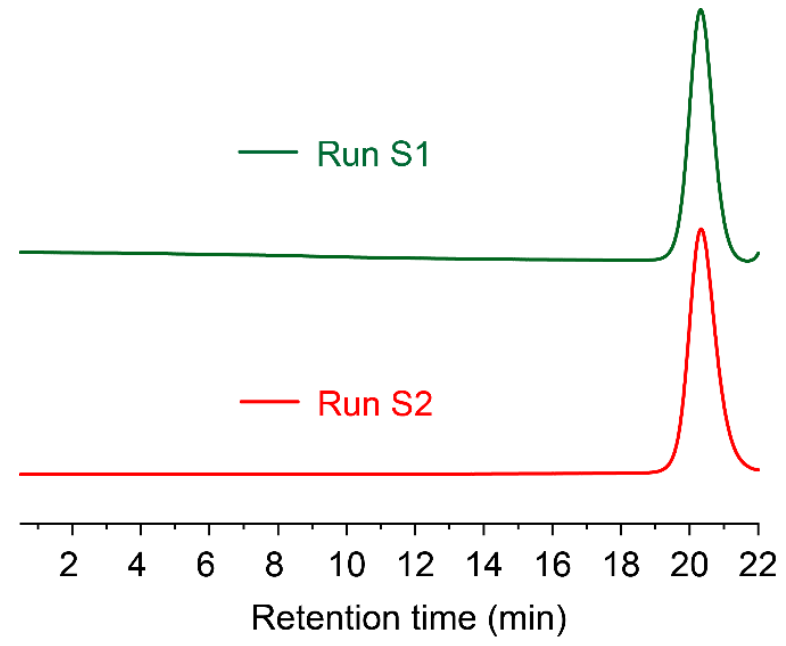

Figure S10. The SEC curves of in situ terpolymerization of DPE, DPE-NSi $2 / \mathrm{DPE}-\mathrm{NMe}_{2}$, and CPVB (Runs S1-2). 


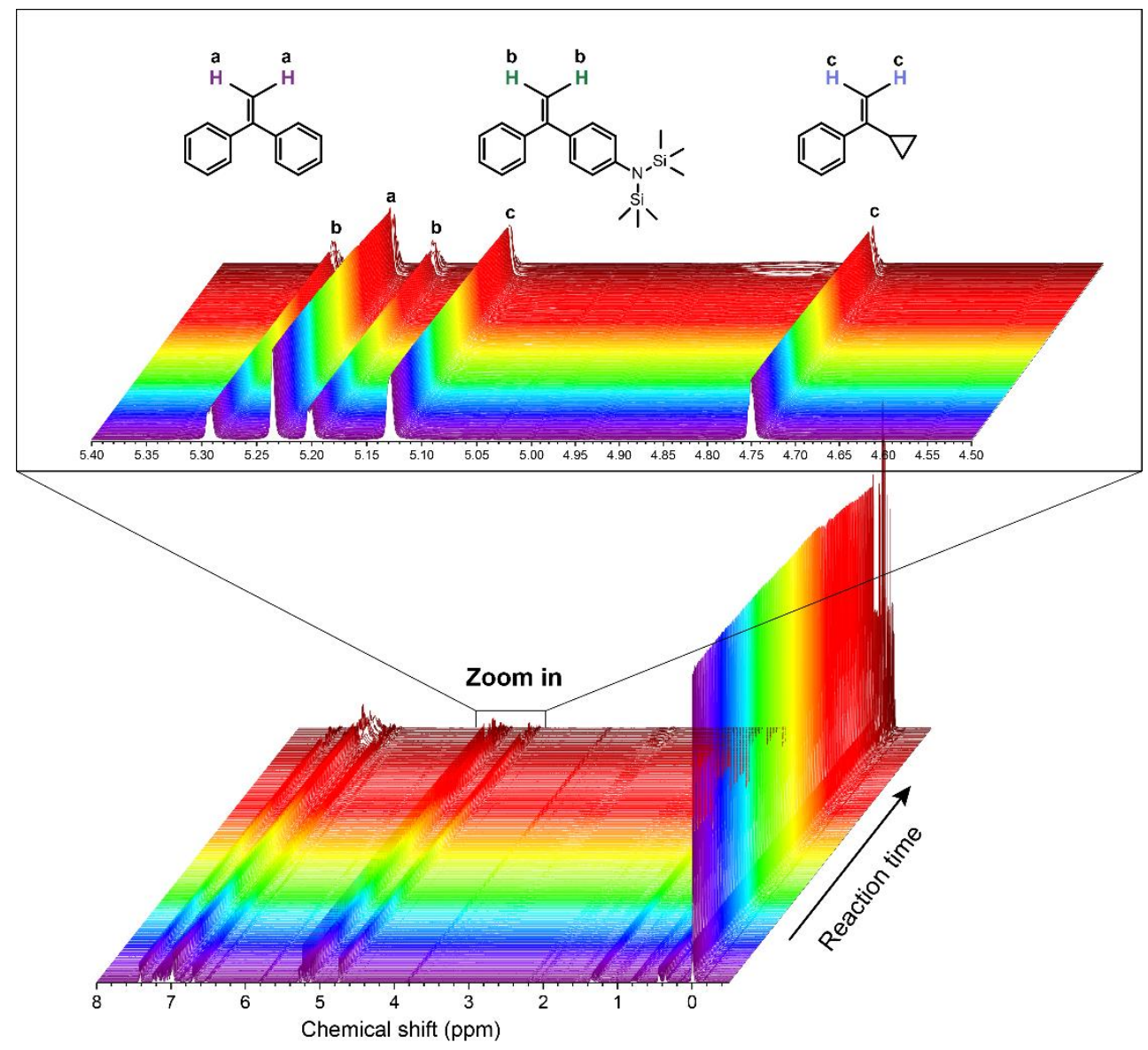

Figure S11. In situ ${ }^{1} \mathrm{H}$ NMR spectra of the terolymerization of DPE and DPE-NSi2 with CPVB (Run S1).

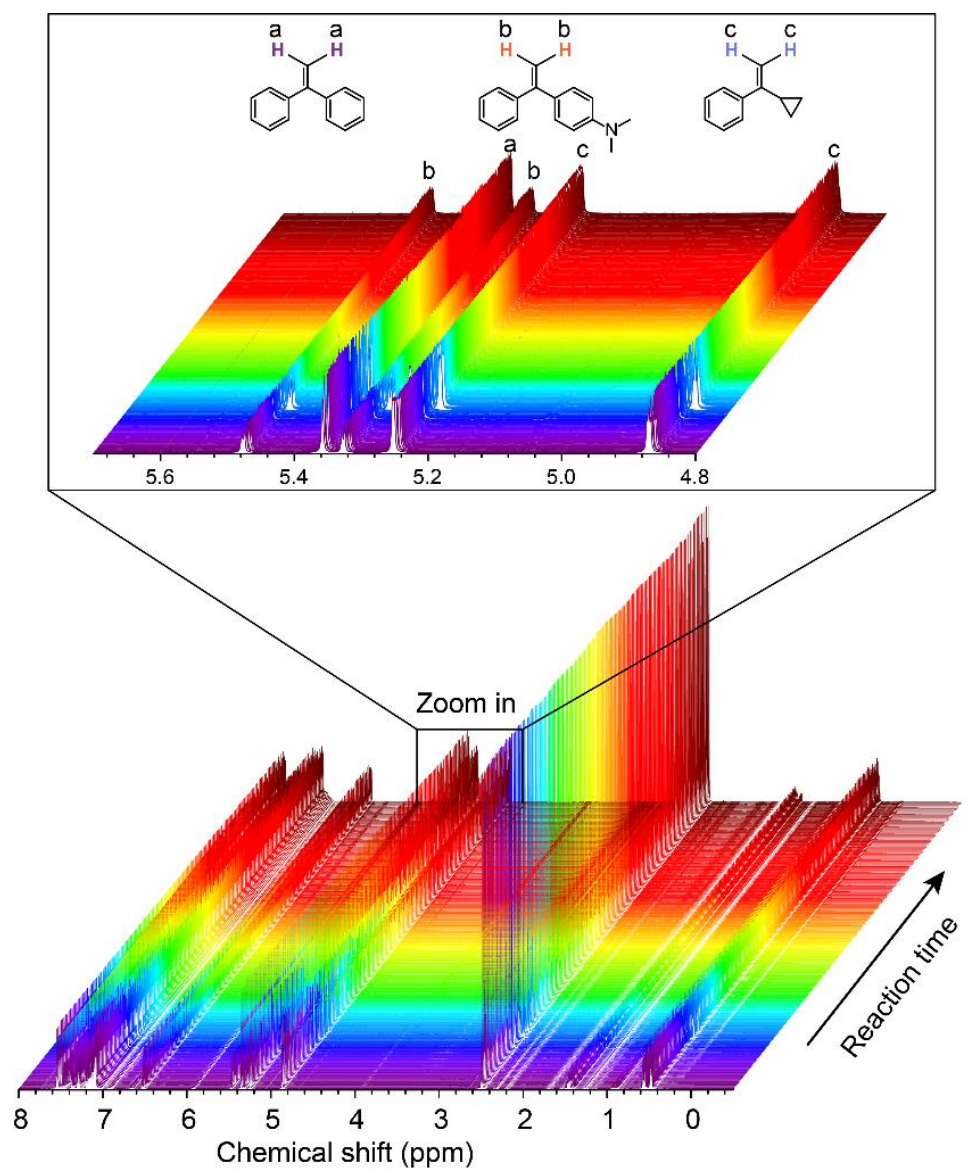

Figure S12. In situ ${ }^{1} \mathrm{H}$ NMR spectra of the terolymerization of DPE and DPE-NMe 2 with CPVB (Run S2). 


\section{The SEC curves of the terpolymers for Runs 6-8}

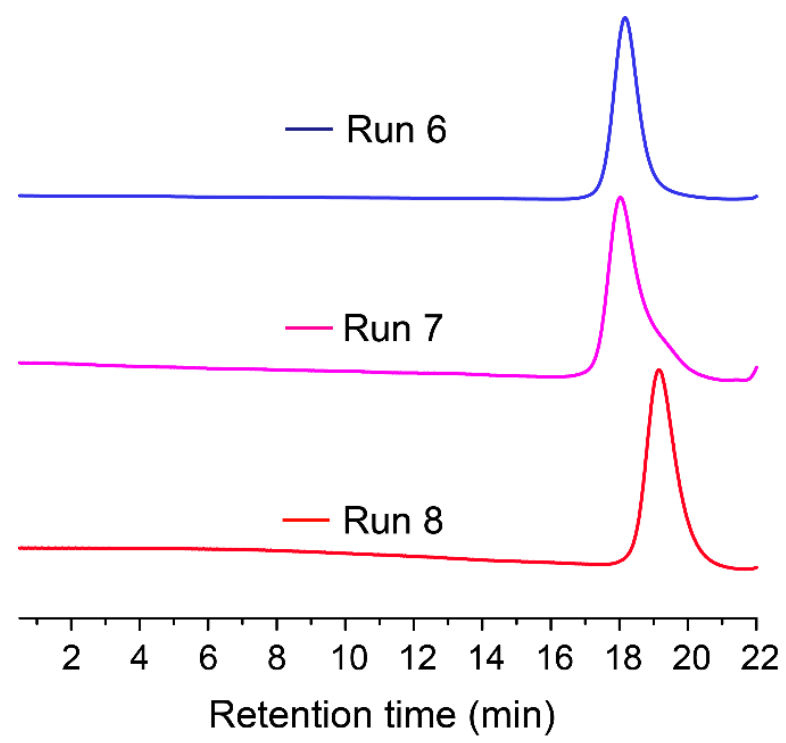

Figure S13. The SEC curves of the terpolymers for Runs 6-8.

\section{REFERENCES}

1. Ma, H.; Wang, Q.; Sang, W.; Han, L.; Liu, P.; Chen, J.; Li, Y.; Wang, Y. Synthesis of Bottlebrush Polystyrenes with Uniform, Alternating, and Gradient Distributions of Brushes Via Living Anionic Polymerization and Hydrosilylation. Macromol. Rapid Commun. 2015, 36, 726-732.

2. Bai, H.; Leng, X.; Han, L.; Yang, L.; Li, C.; Shen, H.; Lei, L.; Zhang, S.; Wang, X.; Ma, H. Thermally Controlled On/Off Switch in a Living Anionic Polymerization of 1-Cyclopropylvinylbenzene with an Anion Migrated Ring-Opening Mechanism. Macromolecules 2020, 53, 9200-9207.

3. Shen, H. Y.; Ma, H. W.; Liu, P. B.; Huang, W.; Han, L.; Li, C.; Li, Y. Facile Synthesis of In-Chain, Multicomponent, Functionalized Polymers via Living Anionic Copolymerization through the Ugi FourComponent Reaction (Ugi-4CR). Macromol. Rapid Commun. 2017, 38, 1700353.

4. Liu, P.; Ma, H.; Huang, W.; Han, L.; Hao, X.; Shen, H.; Bai, Y.; Li, Y. Sequence Regulation in the Living Anionic Copolymerization of Styrene and 1-(4-Dimethylaminophenyl)-1-phenylethylene by Modification with Different Additives. Polym. Chem. 2017, 8, 1778-1789.

5. Suzuki, T.; Tsuji, Y.; Takegami, Y.; Harwood, H. J. Microstructure of Poly(2-phenylbutadiene) Prepared by Anionic Initiators. Macromolecules 1979, 12, 234-239. 